\title{
Investigation of Opportunities of the Practical Application of the Augmented Reality Technologies in the Information and Educative Environment for Mining Engineers Training in the Higher Education Establishment
}

\author{
Snizhana O. Zelinska ${ }^{\text {[0000-0002-3071-5192] }}$, Albert A. Azaryan²[0000-0003-0892-8332] \\ and Volodymyr A. Azaryan \\ ${ }^{1}$ Kryvyi Rih State Pedagogical University, 54, Gagarina Ave., Kryvyi Rih, 50086, Ukraine \\ ${ }^{2}$ State Institution of Higher Education "Kryvyi Rih National University", \\ 11, Vitali Matusevich St., Kryvyi Rih, 50027, Ukraine \\ zvit-zss@ukr.net
}

\begin{abstract}
The augmented reality technologies allow receiving the necessary data about the environment and improvement of the information perception. Application of the augmented reality technologies in the information and educative environment of the higher education establishment will allow receiving the additional instrumental means for education quality increasing. Application of the corresponding instrumental means, to which the platforms of the augmented reality Vuforia, ARToolKit, Kudan can be referred, will allow presenting the lecturers the necessary tools for making of the augmented reality academic programs.
\end{abstract}

Keywords: augmented reality, virtual object, applied software application, platform of the augmented reality, information and educative environment.

\section{Introduction}

The topicality of making this investigation is caused by the following reason. Nowadays the active implementation of the various information and communicative technologies is observed practically in all the spheres of human life activity, and especially in the educative process.

One of the leading and promising technologies is the technology of augmented reality. Its popularity is observed to a marked degree during the recent years. It initiated the rash progress of the wide range of the developments in the field of the augmented reality. At the same time, it is necessary to mention that implementation of any technology deals with the definite advantages and disadvantages. The main disadvantage of the augmented reality technologies is practically the full absence of the documentation support, and their advantage is the obvious availability and receiving the universal tools in teaching any subjects. 
The various aspects of application of the augmented reality technologies as the component of the pedagogical process were examined by Vsevolod A. Serbin and Nadezhda N. Zilberman [13]. The subject of the investigation of the group of the authors (Viktoriia A. Bakhareva, Artem V. Feshchenko, Yevhenii O. Modlo, Serhiy O. Semerikov, Vsevolod A. Serbin, Viktoriia V. Tkachuk, Yuliia V. Yechkalo, Uliana S. Zakharova $[2 ; 7])$ were the technologies of the virtual and augmented reality in the educative environment of the higher education establishment. The classification and the perspective trends of the augmented reality technologies application are given in the works of Boris S. Iakovlev and Sergei I. Pustov $[11 ; 12]$. However, it is necessary to mention that there are a great amount of the separate data in the frame of the examining theme. Each researcher pays his attention to the characteristics in which he is interested. This fact does not allow receiving the entire system of the practical application of the augmented reality technologies in the subject sphere. That is why it is necessary to make additional investigations in the field of the augmented reality technologies in the information and educative environment of the higher education establishment.

\section{The Aim and Objectives of the Study}

The aim of the article is to study the possibilities of the augmented reality technologies in the information and educative environment of the higher education establishment.

According to the aim, the necessity of raising and determining the following tasks was defined: to give the characteristic for the definition "the augmented reality technology"; to analyze the possibilities of the augmented reality technologies application; to describe the possibilities of the augmented reality platforms - Vuforia, ARToolKit, Kudan; to outline the prospects for using augmented reality technologies in mining and professional training.

\section{Discussion and Results}

The augmented reality (AR) is a term appeared in the IT field. Originally, it was used for indication of the virtual information imposition technology on the real surrounding world [9]. The development and active implementation of the augmented reality technologies in the fields of medicine, science, industry, manufacture, social communications and in the other fields sped up the necessity of comprehension of the social consequences of their influence. According to John C. Havens, they are displayed in changing the methods of the social interaction. In particular, he thinks that the augmented reality is not just a technology but it is the most efficient method of the direct interaction with the digital data [3].

Nowadays it became obvious that the technological interpretation of the augmented reality is too narrow. The augmented reality is not just a new technology but it is the unprecedented environment of human habitation which needs being investigated in the theoretical comprehension and prognostication of the perspectives of its application [5]. 
In addition to above-mentioned information, the definition of the augmented reality may be formulated by the following words. The augmented reality is the result of introduction of any sensory data into the field of perception with the goal to add the information about the environment and improvement of information perception; the augmented reality is the apprehended mixed reality created with the computer added elements of the apprehended reality application.

It is essential to mention that nowadays the problematics of the augmented reality application is not practically introduced in the native pedagogical discourse. It also causes the topicality of our appeal to it. It must be noted that two aspects of this problematics can be pointed out. Firstly, it is application of the different augmented reality technologies in the educative process. Secondly, it is comprehension of the heuristic potential of the augmented reality conception.

The foreign experience of the augmented reality technology application in the field of education is described by Nadezhda N. Zilberman and Vsevolod A. Serbin [13]. The various scripts and strategies of the practical application of the augmented reality software programs in the primary and higher education are distinguished. The possibilities of the key services and software program applications for creating the augmented reality segments are described. The classification of the software program applications of the augmented reality is set. The problem of forming of the methodology of the augmented reality technologies practical application in the field of education is raised.

The following types of the educative augmented reality applications are detailed by the author: books with the augmented reality technology which create the peculiar bridge between the digital and physical world; games; educative applications; objects modelling; applications for skills training.

The propositions for classification of the augmented reality technologies were formulated by Boris S. Iakovlev and Sergei I. Pustov. The augmented reality interfaces are divided into autonomous and interactive from the point of view of the interaction with the user $[11 ; 12]$.

Autonomous augmented reality interfaces do not suppose the direct interaction with user, and to a bigger degree, they serve only for the auxiliary data provision about the definite object. Such software program applications can be used for the objects analysis, they are in a man's sight, and one can output the corresponding information about them. For example, a student views the electromechanical systems and apparatus in the demonstration classroom. He receives the additional data about the composition, principles of constructing, analysis and synthesis methods, structural and functional schemes about electromechanical equipment controlling and etc. with the help of the corresponding software program application [10].

In contrast to the autonomous augmented reality technologies, the interactive ones suppose the direct interaction with user. The interactive augmented reality technologies have all the necessary possibilities for tuning the types of the applied augmented segments of data, and they have the possibilities to receive the corresponding answers for the distinguished objects. As a case in functional point of such kind of software program augmented reality application, one can name the programs introducing the possibilities of changing surface colour by means of overlaying (car's colour changing). 
The technological possibilities of the augmented reality can also be divided into some groups: constructing of the virtual objects in the real decorations; augmented reality browser; face identification; distance control of gestures.

The goal of the investigation by Artem V. Feshchenko et al. is to study the possibilities of the devices practical application (for example, Google Glass), technological platform of the virtual reality (vAcademia) and augmented reality services (LayAR, Augment) [2]. It is proved in the work that Google Glass is a sufficient disputed technology for using in the educative practice. Foreign experience of Google Glass using in the field of education cannot be characterized as exclusively positive one. The alternative technology of the augmented reality implemented with the help of the mobile devices and online services is more perspective for using in the higher education establishment. Virtual educative environments application is perceived by the participants as online game. Therefore, the active practical vAcademia application in the educative process of the university is not considered as a reasonable one.

Work of applications with the augmented reality technologies is available now. It is available in the sufficient wide spectrum of devices, one can single out smartphones, tablet computers. Owing to this, practically each person has a technical problem of the direct augmented reality application. It lies in the choice and implementation of the specific unified platform of the augmented reality.

Nowadays there are a great amount of available libraries which intend for creating program augmented reality applications among which one can single out Vuforia, ARToolKit, Kudan.

Vuforia [8] is the platform of the augmented reality and the designer's specialized tools of the software augmented reality (Software Development Kit - SDK) for the mobile devices which were worked out by the company Qualcomm. Vuforia uses the computer vision technologies, and also the simple volumetric real objects technologies and the possibilities of the flat figures tracking at real time.

With the help of the technological augmented reality platform Vuforia, the designer can easily add the computer visualization functional of the virtual 3D-objects into the necessary software application realizing the peculiarities of identification and more exact understanding of the images and objects which are observed in the reality or making 3D-reconstructions of the surrounding and observed environment in the real world.

By means of Vuforia, one can create AR-applications for the wide range of the industrial tasks among which one can single out interactive instructions of the working place, service direction, marketing materials, educative information. The full functional kit is realized for the whole diversity of the possible AR-applications.

ARToolKit [1] is a tracking library with the open source code for creating of the powerful augmented reality applications, which apply the virtual images in the real world. ARToolKit is used for decision of two key problems in the extended reality: real objects tracking and virtual objects interaction.

ARToolKit uses the algorithms of computer vision for solving the problem of snooping the user's point of view. The tracking ARToolKit libraries compute the real position and camera orientation in relation to the physical markers at real time. It allows working out the wide spectrum of the augmented reality applications easily. 
Kudan [6] counts on the high productivity, provides the effective calculations, and it allows receiving the exact and reliable results. There are large numbers of the constructional blocks for Kudan system, the main basis of the code can orient on the majority of the processors' architectures. There is no dependency from availability of the used operational system's functionality. Some classes of processors can be used, beginning from the low-powered processor of the general function and ending the highperformance processors. A great amount of the hardware sensors, beginning from the monocular sensors and stereo cameras ending the visual and inertial depth cameras, are supported.

Every aspect of the system has a great amount of quantity of settings, and one can work with it by means of simple API. It allows tuning the target equipment easily, and afterwards using it.

The enumerated augmented reality libraries give the wide possibilities for the designer, beginning from the different operational systems support ending the deployed instrument kit, which identifies and snoops the objects. Proceeding from the produced requirements for the augmented reality technologies, it becomes obvious to prefer library's using. The library will require the minimal resources investment from the financial point of view and from the point of view of design's complication. The augmented reality platform Vuforia corresponds the set requirements among the abovementioned libraries most of all. Free version availability will allow shortening the financial costs, and Unity support will allow working out software program application, which will support all set of Unity platforms. It simplifies the process of working out and this system supporting (Fig. 1).

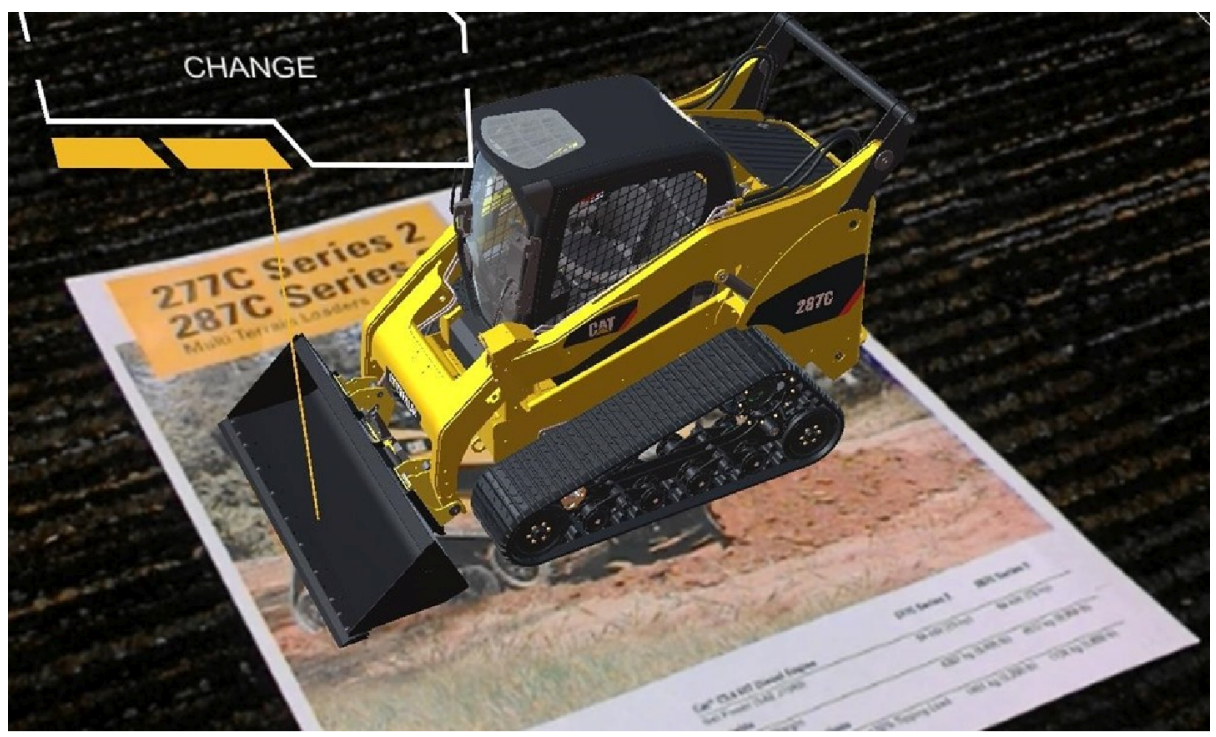

Fig. 1. An example of using Vuforia in the professional training of future mining engineers 
According to Jónatan Jacobs, R.C.W. Webber-Youngman and Etienne van Wyk, potential augmented reality applications in the mining industry is drilling work, navigational aid and operator assistance, maintenance and repair tasks, and the provision of real-time information [4]:

1. When applying augmented reality to assist with drilling practices, through visual guidance on the usage of the drilling equipment or machine, the accuracy and efficiency of drilling could be enhanced. This application could further be expanded to display the real-time location and orientation of the drill bit below surface or within the rock face, as measured through various tracking technologies. The visualisation of such positioning information of the drill bit and rod would then allow for faster reaction and adjustments by operators to improve drilling accuracy (Fig. 2).
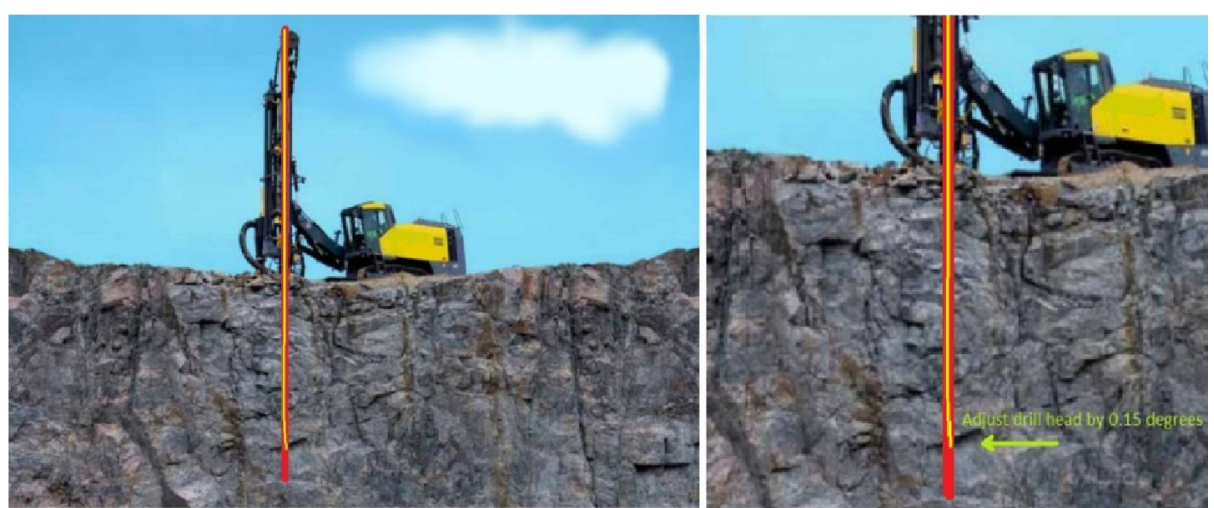

Fig. 2. Augmented drill hole with indicated deflection on the drill head

2. An augmented reality application could be developed for safety purposes that allows mining operators to see hazardous scenarios and objects, such as the road boundaries, approaching vehicles, or the distance to reverse to the dumping site or crusher. The virtual displays over the real world view of the operator could provide various forms of information, as well as a live video feed on "blind-spots" (Fig. 3). 


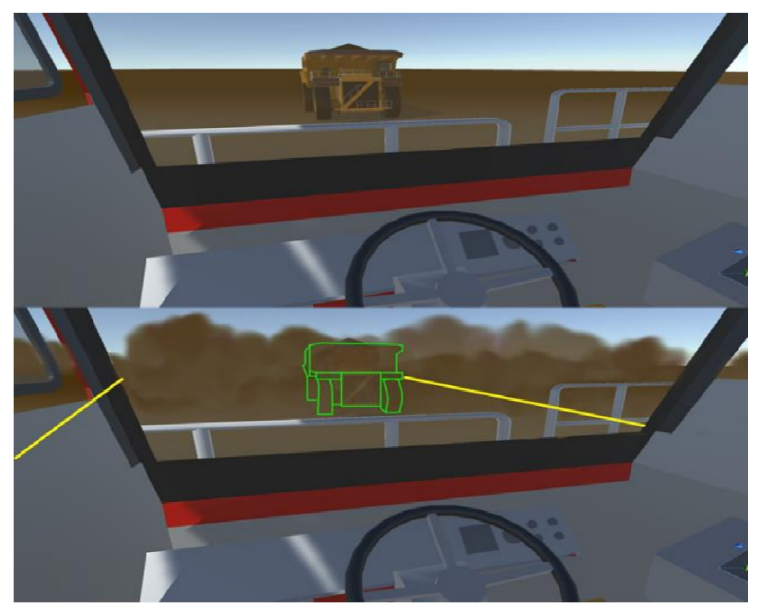

Fig. 3. An augmented outline of an approaching haul truck

3. General maintenance and repair tasks on equipment, machinery and entire systems (e.g. conveyor belts, entire hoisting systems, pipelines etc.) can be conducted with greater efficiency through the utilisation of augmented reality. Essential information can be recalled at the working site, in real-time, and displayed. This could include information on various parts and devices, as well as where they are stored or instructions on how to remove or replace them. Other equipment or machinery information could also be displayed such as current air or pneumatic pressures, fluid levels or the required torque to fasten or loosen a nut (Fig. 4).

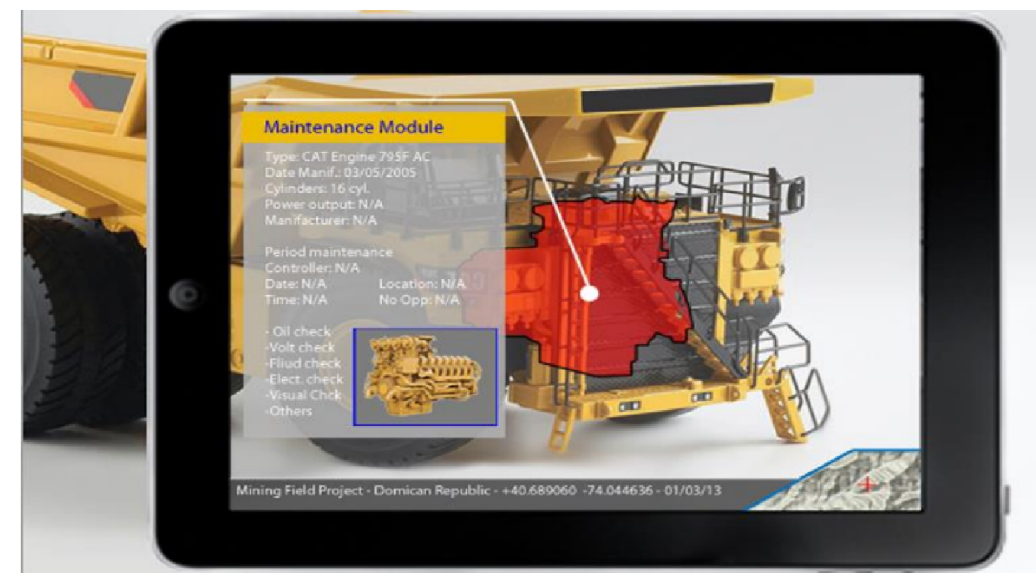

Fig. 4. Example of an augmented reality application for maintenance of a haul truck

4. Augmented reality application could go further to provide real-time guidance and assistance with step-by-step instructions on how to complete a specified task. Along with the ability to recall virtual equipment manuals or any information required to 
perform the work, such an application could bolster task efficiencies. In the same manner, assistance can be provided to perform effective inspections in order to reduce the risk of unscheduled maintenance requirements (Fig. 5).

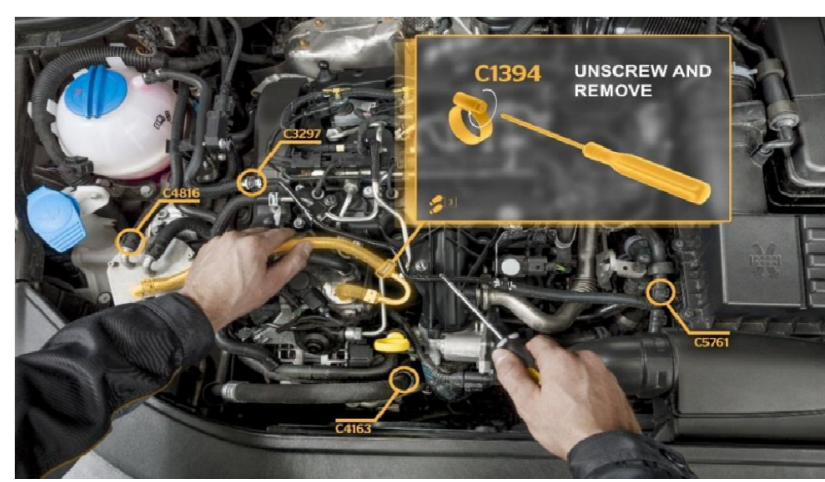

Fig. 5. Augmented maintenance on an engine

5. Augmented reality could provide helpful and potentially lifesaving information. An augmented reality system could be combined with proximity detection technologies to detect dangerous equipment and warn personnel to maintain a safe following distance. Another potential application is to combine augmented reality with other software systems to form a new integrated technological system (Fig. 6).

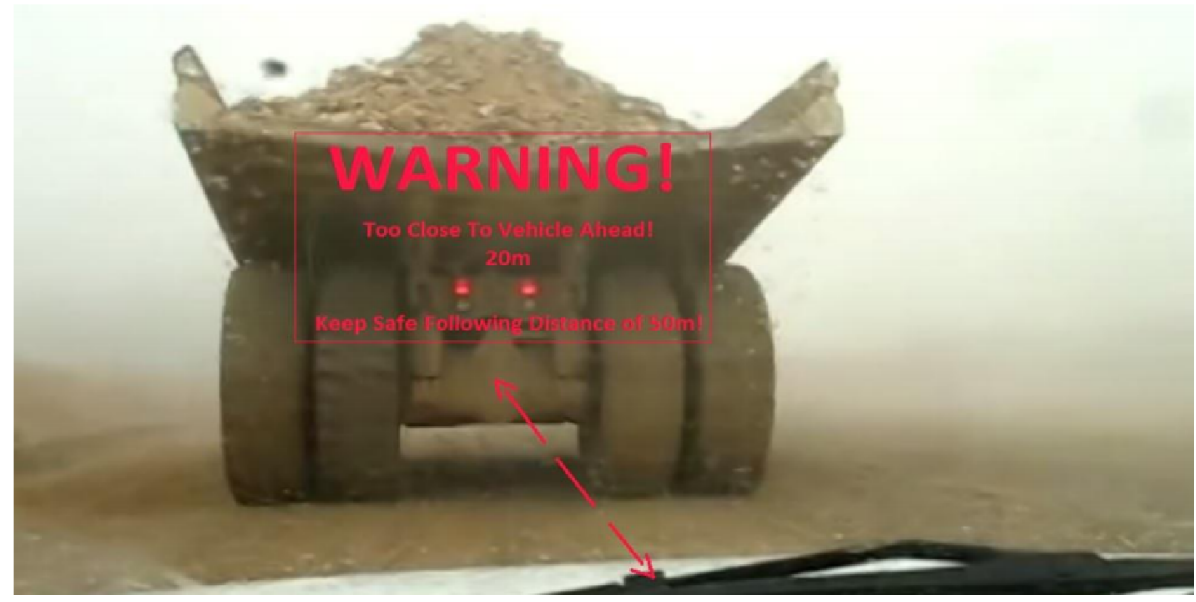

Fig. 6. Real-time augmented reality information in vehicles

The SWOT-analysis of potential augmented applications for the mining industry allowed the authors [4] to highlight the following

\section{- Strengths:}


- Fewer mishaps when completing tasks.

- Expandable new technology.

- Consists of several technologies and/or systems.

- Faster task completion times.

- Can enhance communication and bridge long distances through collaboration.

- Can bridge language barriers.

- Increased awareness.

- Instant access to information, right at the workplace.

- Information is in real time.

- Can work with and connect numerous other systems and technologies.

- Adds value to the other systems/technologies that it is linked to.

- Interactive technological applications.

- Better memory retention.

- Reduced risk of inaccurate or wrong perceptions.

- Elimination or reduction of mundane tasks.

- Increased task efficiency.

- Reduced operating costs.

- Reduced labour requirements

- Reduced reliance on specialist personnel/contractor skills

- Weaknesses:

- Colour blindness factor.

- Job loss/reduction.

- Dependent on other technological systems, devices, knowledge/information source or patents.

- Moderately high costs when various technologies need to be acquired and combined.

- Internet or local server access is required.

- Additional hardware and software requirements.

- Limited visual space in human field of vision.

- System is only as good as the software coding that runs it.

- Reduces human skill improvement.

- Computer system is unable to improve and grow like a person.

- Retraining or additional training requirements.

- Size/storage limitations on mobile display devices.

- Hardware limitations.

- Dependent on human interaction.

- Opportunities:

- Higher task efficiency.

- Higher brain functionality.

- Increase safety to zero harm.

- Threats:

- New/foreign concept.

- New ground/unknown territory.

- Augmented reality often means radical change. 
- Technological incompetence.

- Too much reliance on technology.

- Poor synergy between components.

\section{Conclusion}

In the capacity of the advantages of the augmented reality technologies application one can name interactivity, simple application, possibility of inclusion into the large information context, using of the effect of a student's surprise.

Nevertheless, there are some restrictions of this technology application. First of all, they deal with the technical peculiarities of the augmented reality technologies practical realization. The screen of the user's device restricts the augmented reality. Success of the marker's identification depends on many factors. They are lighting, angle of the user's camera, camera's quality. The augmented reality applications can interpret only a two-dimensional image.

Thus, there is no purposeful implementation of the augmented reality technologies into the educational process nowadays, and there is an extremely little quantity of the similar applied software decisions. Nevertheless, many IT specialists have the similar opinion. They think the augmented reality's future in the various fields of the human life activity has rather great prospects, and eventually the augmented reality technologies in the field of education lead out the system of education on the qualitative new level.

As a whole, it may be said that nowadays the augmented reality technologies in the field of education are on the stage of their coming into being. Taking into account the prospects of their development, it is necessary to conduct analytics of the foreign experience and to perform educational experiments with the augmented reality at native schools and higher education establishments.

\section{References}

1. ARToolKit. https://github.com/artoolkit (2018). Accessed 26 Jan 2018

2. Feshchenko, A.V., Bakhareva, V.A., Zakharova, U.S., Serbin, V.A.: Tekhnologii virtualnoi i dopolnennoi realnosti v obrazovatelnoi srede vuza. Open and distance education. 4(60), 12-20 (2015). doi:10.17223/16095944/60/2

3. Havens, J.C.: The Impending Social Consequences of Augmented Reality. Mashable. http://mashable.com/2013/02/08/augmented-reality-future (2013). Accessed 25 Dec 2017

4. Jacobs, J., Webber-Youngman, R.C.W., van Wyk, E.: Potential Augmented Reality Applications in the Mining Industry. ResearchGate (2016). doi:10.13140/RG.2.2.27751.44961

5. Kislova, O.N.: "Dopolnennaia realnost" skvoz prizmu internet-praktik sovremen-nogo studenchestva ("Augmented reality" through the prism of the modern students' internet-practice). Metodolohiia, teoriia ta praktyka sotsiolohichnoho analizu suchasnoho suspilstva. 20, 351-356 (2014)

6. Kudan. https://kudan.readme.io (2017). Accessed 29 Jan 2018

7. Modlo, E.O., Echkalo, Yu.V., Semerikov, S.O., Tkachuk, V.V.: Vykorystannia tekhnolohii dopovnenoi realnosti u mobilno oriientovanomu seredovyshchi navchannia VNZ (Using 
technology of augmented reality in a mobile-based learning environment of the higher educational institution). Naukovi zapysky, Seriia: Problemy metodyky fizyko-matematychnoi i tekhnolohichnoi osvity. 11(1), 93-100 (2017)

8. PTC Inc.: Vuforia | Augmented Reality. https://www.vuforia.com (2018). Accessed 17 Jan 2018

9. Semerikov, S.O., Striuk, A.M., Slovak, K.I., Rashevska, N.V., Yechkalo, Yu.V.: Liudyna z kompiuternym oblychchiam (do 80-richchia Aivena Edvarda Sazerlenda) (A man with a computer face (to the 80th anniversary of Ivan Edward Sutherland)). New computer technology. 16, 9-24 (2018)

10. Striuk, A., Rassovytska, M., Shokaliuk, S.: Using Blippar Augmented Reality Browser in the Practical Training of Mechanical Engineers. In: Ermolayev, V., Suárez-Figueroa, M.C., Yakovyna, V., Kharchenko, V., Kobets, V., Kravtsov, H., Peschanenko, V., Prytula, Ya., Nikitchenko, M., Spivakovsky A. (eds.) Proceedings of the 14th International Conference on ICT in Education, Research and Industrial Applications. Integration, Harmonization and Knowledge Transfer (ICTERI, 2018), Kyiv, Ukraine, 14-17 May 2018, vol. II: Workshops. CEUR Workshop Proceedings (CEUR-WS.org), vol. 2104, pp. 412-419 (2018)

11. Yakovlev, B.S., Pustov, S.I.: Istoriia, osobennosti i perspektivy tekhnologii dopolnennoi realnosti (History, features and prospects of the augmented reality). Izvestiia TulGU, Tekhnicheskie nauki. 3, 479-484 (2013)

12. Yakovlev, B.S., Pustov, S.I.: Klassifikatciia i perspektivnye napravleniia ispolzovaniia tekhnologii dopolnennoi realnosti (Classification and promising application augmented reality). Izvestiia TulGU, Tekhnicheskie nauki. 3, 484-492 (2013)

13. Zilberman, N.N., Serbin, V.A.: Vozmozhnosti ispolzovaniia prilozhenii dopolnennoi realnosti v obrazovanii (The possibilities of using augmented reality applications in education). Open and distance education. 4(56), 28-33 (2014) 